\title{
A Case Study on Speed Behavior Determination Via Average Speed Enforcement at The Akdeniz University Campus Area
}

\author{
Arzu Ilgaz ${ }^{a *}$ and Mehmet Saltan ${ }^{b}$ \\ ${ }^{a}$ Department of Building Works and Technical Head, Akdeniz University, Antalya, Turkey 1 \\ ${ }^{b}$ Department of Civil Engineering, Suleyman Demirel University, Isparta, Turkey 2 \\ ${ }^{*}$ E-mail address: arzuilgaz@akdeniz.edu.tr \\ ORCID numbers of authors: \\ 0000-0003-4266-7519a, 0000-0001-6221-4918
}

Received date: June 2017

Accepted date: September 2017

\begin{abstract}
Average speed enforcement is a new traffic safety measure that is used increasingly in recent years. The advantage of this enforcement system is that the average speed of drivers can be recorded along a whole section in order to determine whether they obey the speed limits or not. In this study, the speeding behavior and violation behaviors of drivers were quantified in accordance with only the traffic signs and the provided speed limits with no penal sanctions on 11 sections at the Akdeniz. University with speed limits of 20,30 and $50 \mathrm{~km} / \mathrm{h}$. Two month average travel speeds of each vehicle that passes from the application sections were measured via mobile average speed enforcement system without announcing to the drivers which were then analyzed via Independent Sample t test. The results of the speed study indicate that they differ on sections with different physical properties according to the preferences of drivers. Low compliance in general to the speed limits indicate non-optimal speed limits. A higher compliance to the speed limits may be ensured by an enforcement measure in the follow-up of the violations.
\end{abstract}

Keywords: Average speed enforcement, average speed, Independent Sample t test.

\section{Introduction}

Speed is one of the primary concepts of traffic engineering and is the most important factor that travelers consider when choosing an alternative route or the type of transportation. Vehicle speeds are subject to the physical characteristics of the roads, the ratio of intervention from the road side, weather condition, existence of other vehicles and speed limits in addition to the talent of the drivers and the characteristics of the vehicles [1].

Various speed enforcement systems are used in each country to solve the issue of speeding in traffic [2]. The most common of these systems that is used on the urban roads and expressways is police inspection system via radar device [3]. In this system, spot speeds of the vehicles are determined at locations where the radar control is made and a monetary fine is prepared for the drivers if their speeds exceed the pre-determined speed limits. If the driver knows the location of the police radar control, he/she may avoid fines by decreasing the speed of the vehicle while approaching to that location and thus passing by within the speed limit. Therefore, spot speed betterment occurs only at and around the location where the radar is placed. This betterment does not represent a certain road network and cannot be effective for long distances. Another disadvantage of the current system is the need for a large number of police staff, vehicles, time 
and resources [4,5]. The drivers display unsteady speeding behaviors as a result of these applications which decrease police efficiency and cannot be evaluated fairly. However, the objective of the traffic inspections carried out is not to control and check the drivers but to decrease traffic accidents which cause deaths and injuries [6].

The objective of this article is to seek a solution to the problem of overspeeding with the average speed enforcement (ASE) method which is a new method with less such disadvantages. The main task of ASE is to measure the average speeds of motorized vehicles for speed control and traffic enforcement purposes. This system is a new traffic enforcement measure with increasing use in recent years for speed limit enforcement [7-13].The advantage of the system is that the cameras measure the average speed of vehicles along a significant distance instead of controlling the speeds of the vehicles at a certain spot on the road. Thus, ASE aims a sustainable speeding behavior which may be much more acceptable for the public in comparison with single camera applications [11,12,14-23].

In this study, the outline of the scope of the speeding problem was drawn and the current need for developing innovative approaches to speed management and especially speed enforcement application was emphasized. Akdeniz University campus region is selected as study area. Pedestrians and vehicles mostly have to use the same space in the campus thereby inviting "pedestrian strike type accidents". In addition, the average number of "recorded accidents" on the campus is around 10 annually according to the university archives. Such dangerous accidents in the campus should not be allowed. Overspeeding vehicle intensity attracts attention in the campus despite the traffic signs indicating " 20,30 and $50 \mathrm{~km} / \mathrm{h}$ " speed limits. There are speed bumps as measures against overspeeding; however speed bumps have various disadvantages. For example; speed bumps may damage various parts of the vehicles [24].This study focuses on the examination of the speeding behavior of drivers according to section preference using a mobile ASE. The average speeds of the drivers are calculated at 11 sections in this method that was carried out unannounced to drivers; the speeding, overspeeding and compliance behaviors of drivers subject to different sections and different speed limits are analyzed and suggestions are made for a higher compliance to the speed limits. The fact that no prior information was given by the media along with the combined effect due to the absence of enforcement studies has enabled the acquired data to be unbiased thereby ensuring that the study is of high value. The difference of this study with the applications used in our country is that data acquisition can be carried out at the desired location and time since license reading cameras were setup not on a fixed structure but on mobile vehicles. In addition, such applications were limited by expressway conditions in the past; however, sections in a university campus have been used for the first time in this study.

\section{Background}

Speed is decided upon by the driver and the drivers generally prefer speeds at which they feel safe. Whereas high speeds decrease the travel time thereby making a positive impact with regard to economy and activity. A significant decrease in travel time contributes to the development of the national and regional economy [1]. However, overspeeding is a significant traffic safety issue on all types of sections $[1,25,26]$. Driving at speeds above the predetermined speed limits may increase traffic accident ratio [26].

Speed limits indicate the maximum speed determined by law at which the driver may drive his/her vehicle under good road and traffic conditions. They are indicated by traffic regulatory signs according to different section classes, vehicle types and residential area characteristics. It 
is against the law to drive at speeds above the speed limit. Speed limits may be enforced by way of legal regulations or traffic signs $[1,27]$.

It has been suggested by many studies on speed enforcement that speeding behavior can be socially accepted when the speed is not perceived as excessive [28,29]. Moreover, drivers adjust their driving behaviors to the enforcement application methods as they change over time. Driver behaviors such as learning where the zone is and changing the behavior only at the zones where there is speed enforcement enable the drivers to avoid fines. A series of researchers emphasized that avoiding fines encourages the drivers to behave continuously against the law $[29,30]$. Thus, there is a need to develop new speed enforcement approaches that will have a wider application zone resulting in a decrease in avoidance and related fines [29].

Speed definitions that enable clear measurements are required from a researcher perspective. Typically, two types of speed data are collected: 'spot speed' and 'average speed'. The spot speed of a vehicle is the independent speed of the vehicle as it passes from a certain spot on the road. Whereas average speed is the corridor speed of the vehicle between two points on the road that are separated by a certain distance [31].

ASE includes the placement of two or more cameras along a section of the road network (Fig. 1). The licence plate and/or vehicle and vehicle registration data are taken for each vehicle entering the system from the first camera location and additional images and data taken at the following camera positions are added which are then matched with the first data. Afterwards, Automatic Number Plate Recognition (ANPR) and Optical Character Recognition (OCR) technology are used for matching the vehicle registration data [10-12,16,19,20,23,29,32-35]. If the determined vehicle speed exceeds the legal speed limit for that section, images and violation data (e.g.: time, date, speed etc.) are transferred to a central processing unit from the local processor via a communication network. Afterwards, a violation notice is prepared for the verified violations whereas data for vehicles with no violation are deleted in a certain period of time $[11,16,29,35]$.Studies carried out for evaluating the effects of ASE on the vehicle speed prove the high ratio of positive impact of the application on a series of speed criteria. These criteria are; "average speeds, 85 percentile speeds, ratio of speeding vehicles, speed variance [11].

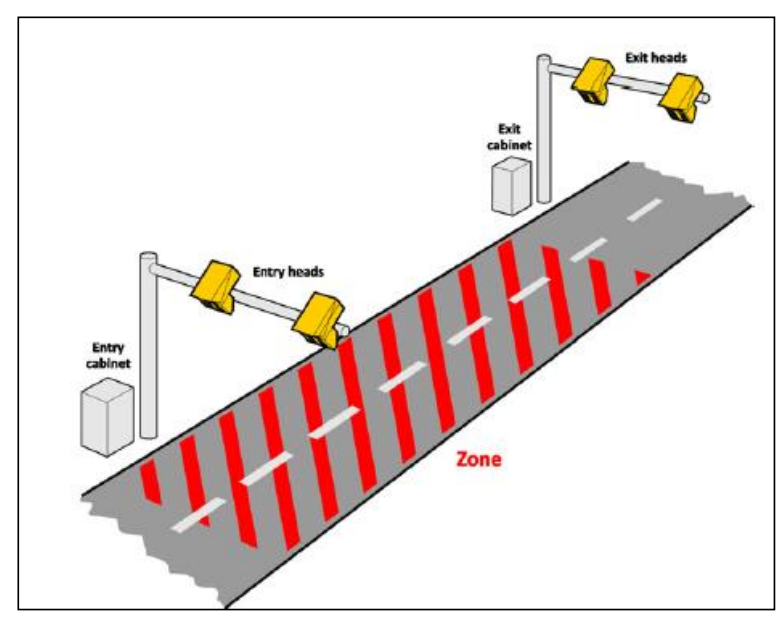

Fig. 1. Average speed application [11]

Driver behaviors show significant differences when compared according to spot speed and average speed cameras. The speed perception zone is different for each camera type which in 
turn determines the 'effect zone' of the cameras. Even though spot speed cameras make up a system that is effective at a certain location with known accident history, average speed cameras have greater effect on the drivers since they are applied over a much longer section $[11,12,14$ 23]. Keenan (2002) put forth when commenting on the advantages of the average speed technology that spot speed measurement cameras have effects specific to the field, however that the ASE enforcement application on drivers and their speeds creates an effect on longer distances even though it is visible only at the beginning and end of the section. In addition, Keenan (2002) also recorded the following in the study: "majority of the drivers the behaviors of which were observed around the spot speed camera zones changed their behaviors near the cameras, suddenly stepped on the brakes 50 meters before the camera and also suddenly increased their speeds after passing by the camera. The most disquieting issue about this is that the accident statistics at zones of certain spot speed cameras have worsened since the installment of the cameras". However, when it is taken into consideration that there is a policy for setting up the fixed camera zones in an apparent manner and placing advanced camera warning signs decreases the possibility of surprising the drivers [15,32]. Hence, ASE eliminates the sudden breaking behavior of drivers when they see the camera and speeding up after they pass the camera thereby eliminating the risks involved (Fig.2) [11,15,18,21,36].

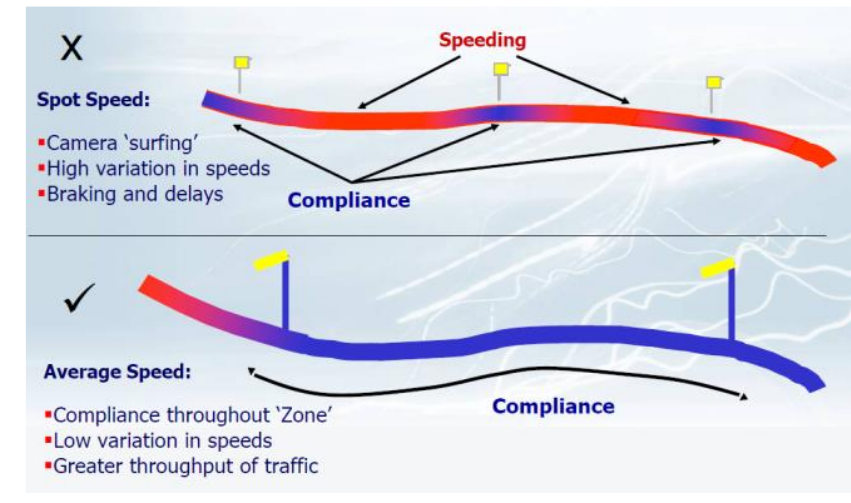

Fig. 2. Driver behaviors at spot speed and average speed zones [8]

\section{Method}

\subsection{Sections and System Installment}

The sections were determined in the light of the following issues: "a)the areas where speed related accidents occur in the campus, b) sections where tendency for speeding is high,c) the sections preferred in general by commuter drivers in the morning and evening traffic, d) refraining from intersections in the application corridor and having low entry/exit volume minor intersections if they cannot be avoided". There are 11 sections on different lengths of mobile ASE (Figure 3), and the average speed limit values applied to these sections are 20, 30 and 50 $\mathrm{km} / \mathrm{h}$ (Table 1). 
Table 1. Properties of ASE installed sections

\begin{tabular}{|c|c|c|c|c|c|c|c|c|c|}
\hline \multirow{2}{*}{$\begin{array}{c}\text { Spot } \\
\text { pair } \\
\text { A } \\
\end{array}$} & \multirow{2}{*}{$\begin{array}{c}\begin{array}{c}\text { Length } \\
\text { (m) }\end{array} \\
908 \\
\end{array}$} & \multirow{2}{*}{$\begin{array}{c}\begin{array}{c}\text { Speed } \\
\text { limit } \\
(\mathbf{k m} / \mathbf{h})\end{array} \\
30 \\
\end{array}$} & \multicolumn{2}{|c|}{$\begin{array}{l}\text { Number of lanes } \\
1^{\text {st }} \text { spot } \quad 2^{\text {nd }} \text { spot }\end{array}$} & \multicolumn{2}{|c|}{$\begin{array}{c}\text { Lane width } \\
(\mathbf{m}) \\
1^{\text {st }} \text { spot } \quad 2^{\text {nd }} \text { spot }\end{array}$} & \multirow{2}{*}{$\begin{array}{c}\begin{array}{c}\text { Number of } \\
\text { intersections }\end{array} \\
4 \\
\end{array}$} & \multirow{2}{*}{$\begin{array}{c}\begin{array}{c}\text { Number of } \\
\text { horizontal } \\
\text { curbs }\end{array} \\
2 \\
\end{array}$} & \multirow{2}{*}{$\begin{array}{c}\begin{array}{c}\text { Number } \\
\text { of chasses }\end{array} \\
3 \\
\end{array}$} \\
\hline & & & 2 & 1 & 3.50 & 3.50 & & & \\
\hline $\mathrm{B}$ & 717 & 30 & 2 & 2 & 3.50 & 3.50 & 3 & - & 3 \\
\hline $\mathrm{C}$ & 890 & 50 & 2 & 2 & 3.50 & 3.50 & 1 & - & 1 \\
\hline D & 890 & 50 & 2 & 2 & 3.50 & 3.50 & 2 & - & 1 \\
\hline $\mathrm{E}$ & 425 & 30 & 2 & 2 & 3.50 & 3.50 & 2 & - & 2 \\
\hline $\mathrm{F}$ & 600 & 20 & 2 & 2 & 3.00 & 3.00 & - & - & - \\
\hline $\mathrm{G}$ & 600 & 20 & 2 & 2 & 3.00 & 3.00 & - & - & - \\
\hline $\mathrm{H}$ & 615 & 30 & 1 & 2 & 3.50 & 3.50 & 3 & 2 & 1 \\
\hline I & 594 & 30 & 2 & 1 & 3.50 & 3.50 & 3 & 2 & - \\
\hline $\mathrm{J}$ & 695 & 30 & 2 & 1 & 3.50 & 3.50 & 2 & 2 & - \\
\hline $\mathrm{K}$ & 695 & 30 & 1 & 2 & 3.50 & 3.50 & 2 & 2 & - \\
\hline
\end{tabular}

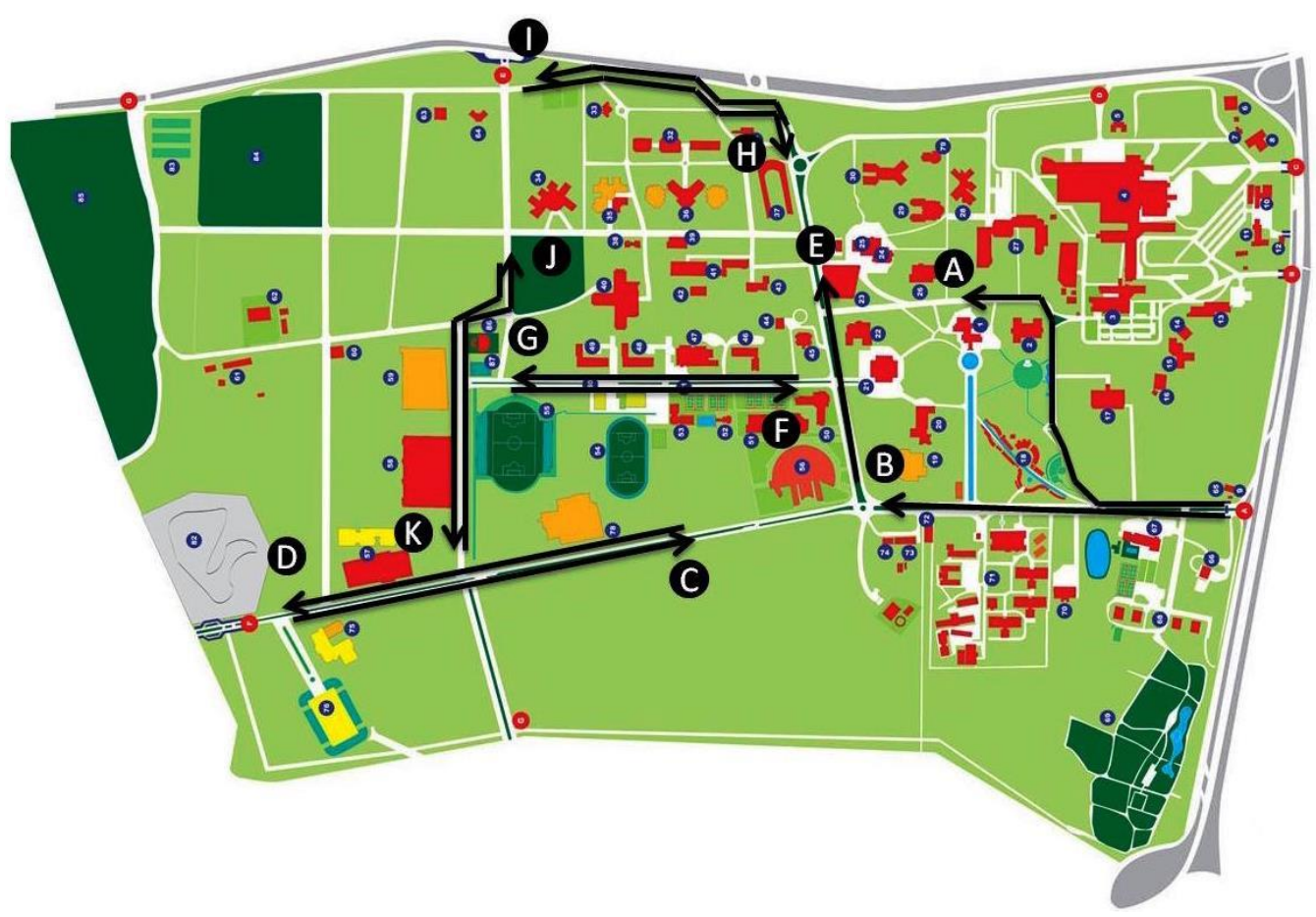

Fig. 3. Average speed corridors

The installed mobile ASE technology has two basic forms: (a) carrying the camera from a fixed spot to another fixed spot when desired and (b) installing a camera on a vehicle. The underlying concept behind carrying the camera from one fixed spot to another is; enforcing driver speed behaviors on a wide zone without the requirement for holistic systems at each fixed spot. The reason for this may be economic or administrative. The economic perspective is simple smaller number of cameras is required. Whereas the administrative reason is not allowing the complaints of drivers regarding the creation of a speed trap. In addition, cameras were camouflaged inside a 'sound system luggage' so that the cameras do not attract the attention of the drivers, that they do not hinder the secrecy of the license plate readings that should be carried out without any announcements to the drivers (in order to acquire objective results from the average speed data) (Fig.4). A sign was placed on the front glass interior of the vehicle which indicates that a 'noise measurement test' is being carried out (Fig.5). 


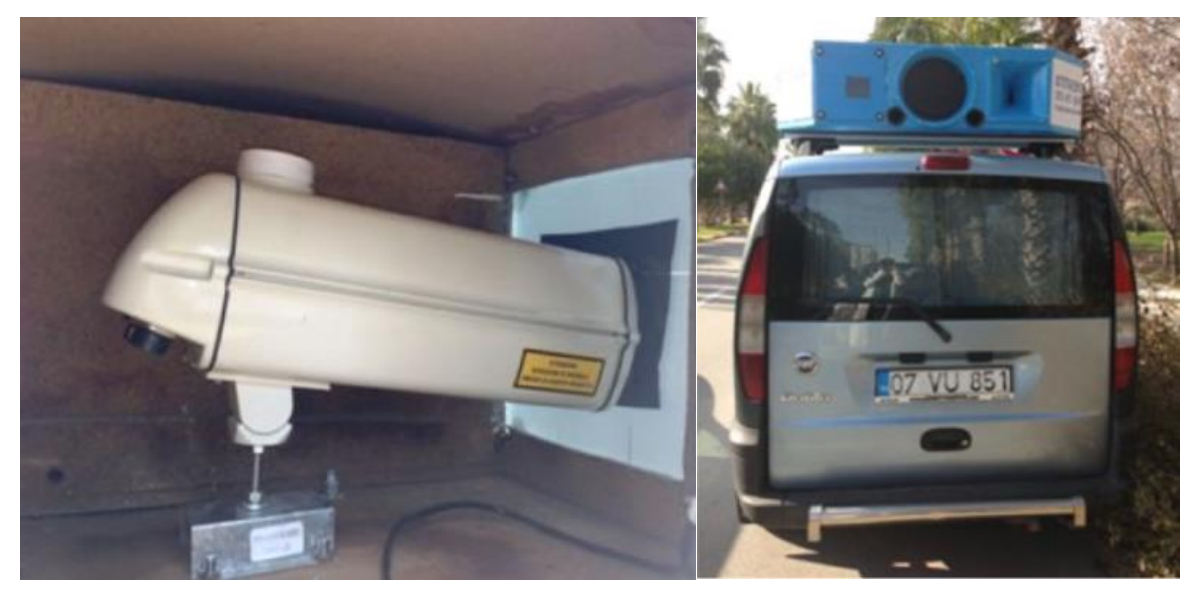

Fig. 4. ANPR setup placed on the vehicle

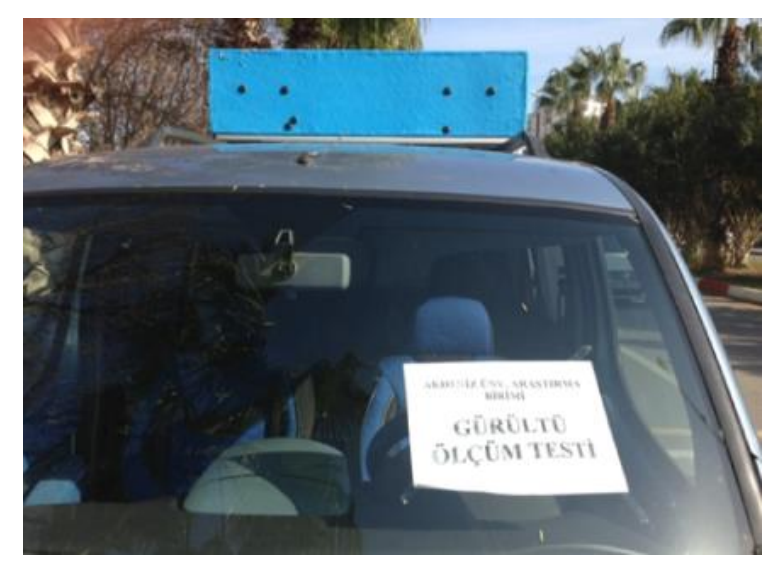

Fig. 5. Announcement (for diversion purposes)

The system operates by detecting the license plates of the vehicles via uninterrupted video flow method and transferring the photographs to the central server.The license plates analyzed via the cameras are transferred to the central server shown in Fig.6 (computer+main software) via wireless internet connection (3G Router) as both writing and photograph (Fig.7).

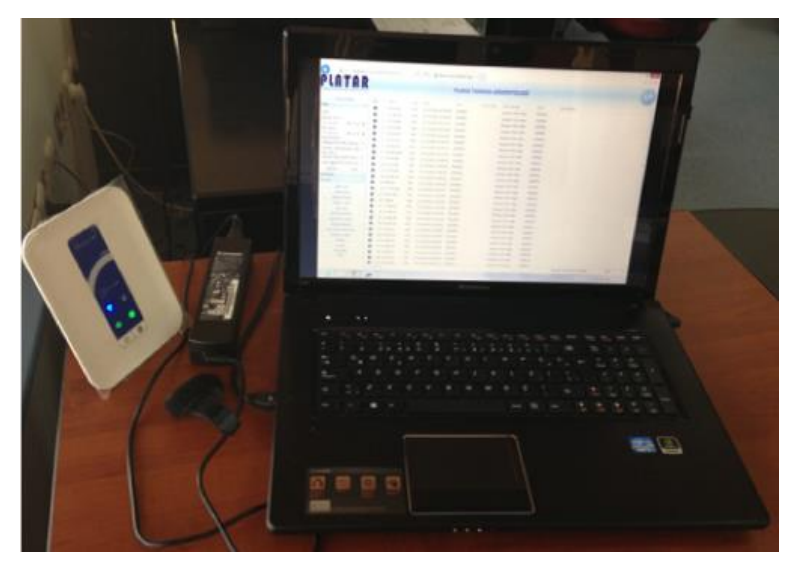

Fig. 6. Central Server 


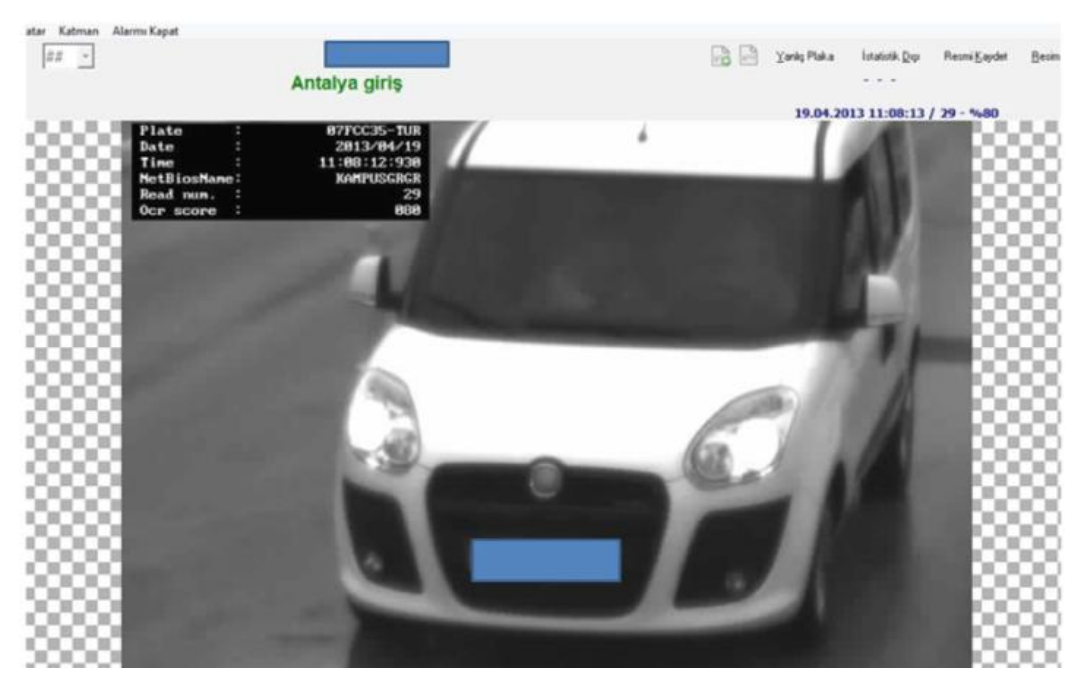

Fig. 7. Vehicle example transferred as a photograph via 3G Router

\subsection{Data Acquisition}

The cameras carried out license plate readings and average speed detection at different ASE corridor and spots during the hours of 08:00-18:00 between the dates of "31 January 2013 - 29 March 2013" for 5 weekdays on parked vehicles. The study period was selected as the spring semester of the university. These dates were the most appropriate for the collection of data. Because there were no holidays and, road construction or accidents on these time durations. The application duration was not announced to the drivers in order to ensure the effectiveness of the acquired results.

\subsection{Method}

The average speed, date and time information can be displayed for the vehicles passing by the $1^{\text {st }}$ and $2^{\text {nd }}$ license plate identification spots via the central server software which may be saved in Excel format. All data saved in Excel format were loaded to SAS (Statistical Analysis Software) which were then subject to various statistical analyses in accordance with the study objectives. The level of significance of the study was determined as 0.05."Frequency, percentage, average, standard deviation and histogram" were used as descriptive statistics when evaluating the speed data in the study. Independent Sample t test was used afterwards in order to determine the differences between the average speeds of drivers who violated and did not violate the speed limits.

\section{Results}

\subsection{Average Speed Results}

On the scope of the study, speeding behaviors of the drivers were examined via mobile ASE. The compliance of the drivers to the speed limits were evaluated on the basis of 'the average travel speeds of the vehicles' passing by each study section. The number of monitored vehicles was 23060 and Table 2 shows the sections included in the study as well as the number of vehicles. 
Table 2. Number of vehicles per measurement spot included in the study

\begin{tabular}{cccc}
\hline Section & $\begin{array}{c}\text { Speed limit } \\
(\mathbf{k m} / \mathbf{h})\end{array}$ & $\begin{array}{c}\text { Section } \\
\text { length }\end{array}$ & $\begin{array}{c}\text { Number of } \\
\text { vehicles }\end{array}$ \\
\hline F & 20 & 600 & 806 \\
G & 20 & 600 & 273 \\
Total & & & $\mathbf{1 0 7 9}$ \\
\hline A & 30 & 908 & 659 \\
B & 30 & 717 & 4962 \\
E & 30 & 425 & 6203 \\
H & 30 & 615 & 1123 \\
I & 30 & 594 & 539 \\
J & 30 & 695 & 2964 \\
K & 30 & 695 & 412 \\
Total & & & $\mathbf{1 6 8 6 2}$ \\
\hline C & 50 & 890 & 3820 \\
D & 50 & 890 & 1299 \\
Total & & & $\mathbf{5 1 1 9}$ \\
\hline Total & & & $\mathbf{2 3 0 6 0}$ \\
\hline
\end{tabular}

Table 3 shows the findings of the data for the mobile ASE installed at 11 different sections. Since the measurements were carried out as secret and no announcements were made regarding the speed limits, the speeds are those that the "drivers are free to choose". There were no different types of traffic flows since the system was installed in a university campus. Flow ratio ranges between 0-10 vehicles per lane per minute and the speeds between ' $10-90 \mathrm{~km} / \mathrm{h}$ ' of the vehicle drivers were included in the analyses. The speed averages of sections $F$ and $G$ exceed the speed limit at a high ratio (139 percentages) according to the following table. Whereas sections with a speed limit of $30 \mathrm{~km} / \mathrm{h}$ have different average speed values each. It was observed that only the speed average of the A1 section is in accordance with the speed limits, whereas section $\mathrm{J}$ has the highest speed average $(45.01 \mathrm{~km} / \mathrm{h})$. The differences between the speeds of the vehicles for each section with different speed limits of 20,30 and $50 \mathrm{~km} / \mathrm{h}$ were compared according to the standard deviation values. It was observed that the speed difference at $G$ is lower than that of F on sections with a speed limit of $20 \mathrm{~km} / \mathrm{h}$. Sections A and K are those with the highest speed difference between the vehicles among the sections with a speed limit of 30 $\mathrm{km} / \mathrm{h}$. The speed difference at section $\mathrm{D}$ is lower than that of $\mathrm{C}$ for sections with a speed limit of $50 \mathrm{~km} / \mathrm{h}$. Low standard deviation provides proof that the traffic flow in these related sections is better in comparison with other sections as a result of the low standard deviation in the vehicle speeds for those sections.

Table 3. Results obtained from Mobile ASE measurement

\begin{tabular}{ccccccc}
\hline Section & $\begin{array}{c}\text { Speed limit } \\
(\mathbf{k m} / \mathbf{h})\end{array}$ & $\begin{array}{c}\text { Section } \\
\text { length }\end{array}$ & $\begin{array}{c}\text { Number } \\
\text { of } \\
\text { vehicles }\end{array}$ & $\begin{array}{c}\text { Number of } \\
\text { vehicles } \%\end{array}$ & $\begin{array}{c}\text { Speed average } \\
(\mathbf{k m} / \mathbf{h})\end{array}$ & $\begin{array}{c}\text { Standard } \\
\text { Deviation }\end{array}$ \\
\hline F & 20 & 600 & 806 & 3.50 & 47.78 & 12.52 \\
G & 20 & 600 & 273 & 1.18 & 47.91 & 11.32 \\
Total & & & $\mathbf{1 0 7 9}$ & $\mathbf{4 . 6 8}$ & $\mathbf{4 7 . 8 1}$ & $\mathbf{1 2 . 2 2}$ \\
\hline A1 & 30 & 908 & 659 & 2.86 & 28.16 & 6.53 \\
B & 30 & 717 & 4962 & 21.52 & 31.64 & 7.08 \\
E & 30 & 425 & 6203 & 26.90 & 33.37 & 8.48 \\
H & 30 & 615 & 1123 & 4.87 & 37.24 & 8.05 \\
I & 30 & 594 & 539 & 2.34 & 42.81 & 7.62 \\
J & 30 & 695 & 2964 & 12.85 & 45.01 & 7.14 \\
K & 30 & 695 & 412 & 1.79 & 41.81 & 6.81 \\
Total & & & $\mathbf{1 6 8 6 2}$ & $\mathbf{7 3 . 1 2}$ & $\mathbf{3 5 . 4 7}$ & $\mathbf{9 . 2 7}$ \\
\hline C & 50 & 890 & 3820 & 16.57 & 54.27 & 10.74 \\
D & 50 & 890 & 1299 & 5.63 & 53.46 & 8.97 \\
Total & & & $\mathbf{5 1 1 9}$ & $\mathbf{2 2 . 2 0}$ & $\mathbf{5 4 . 0 7}$ & $\mathbf{1 0 . 3 2}$ \\
\hline
\end{tabular}


The percentage of speed distributions in the measurements can be seen in Fig.8 as graphically. It can be observed that the vehicles violate the $20 \mathrm{~km} / \mathrm{h}$ average speed limit in sections $\mathrm{F}$ and $\mathrm{G}$ (Fig.8). Whereas majority of the drivers in section G (85\%) drive with average speeds of 31$65 \mathrm{~km} / \mathrm{h}$, the number of vehicles driving at an average speed has decreased down to $75 \%$ in section F. Section A1 is the section with the lowest average speed distribution among sections with a speed limit of $30 \mathrm{~km} / \mathrm{h}$ despite the fact that no announcement was made. The average speeds at section B and E varied between 26 to $45 \mathrm{~km} / \mathrm{h}$, whereas the average speed for section $\mathrm{H}$ varied between 31 to $45 \mathrm{~km} / \mathrm{h}$. Sections I, J and K were the sections with the highest average speed distribution. These results indicate that the behavior of the drivers to comply the $30 \mathrm{~km} / \mathrm{h}$ speed limit varies from section to section. It means that there is a discrepancy between the sections and the speed limit signs which leads us to think that enforcing the same speed limit at sections with different properties pushes the drivers towards violation. Vehicle drivers have determined their driving speeds not according to the speed limit signs, but to the physical status of the section. The fact that there are no speed bumps on especially sections I, J and K might have caused a high speed distribution in comparison with other sections. Whereas majority of the drivers in the $\mathrm{C}$ section ( $86 \%$ ) from among sections with a speed limit of $50 \mathrm{~km} / \mathrm{h}$ drive at speeds varying between $41-70 \mathrm{~km} / \mathrm{h}$, the number of vehicles driving at average speed increased up to $91 \%$ at $\mathrm{D}$ section.

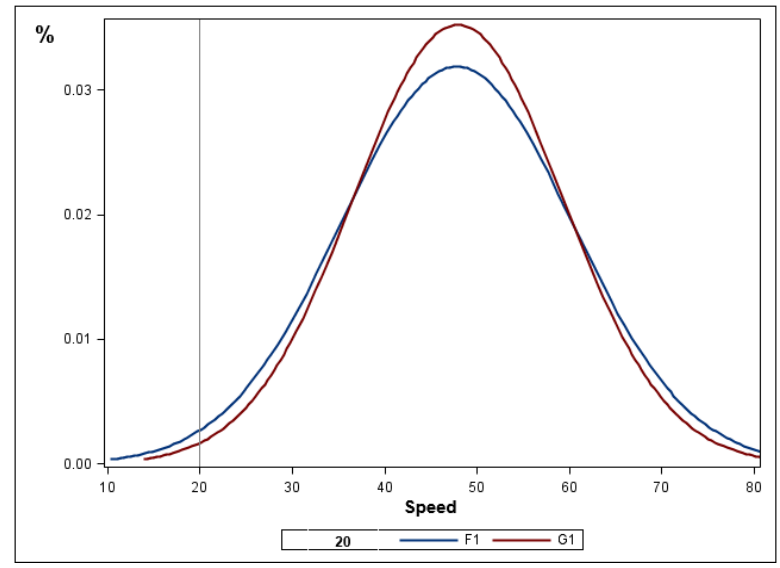

a) Sections $F$ and $G$

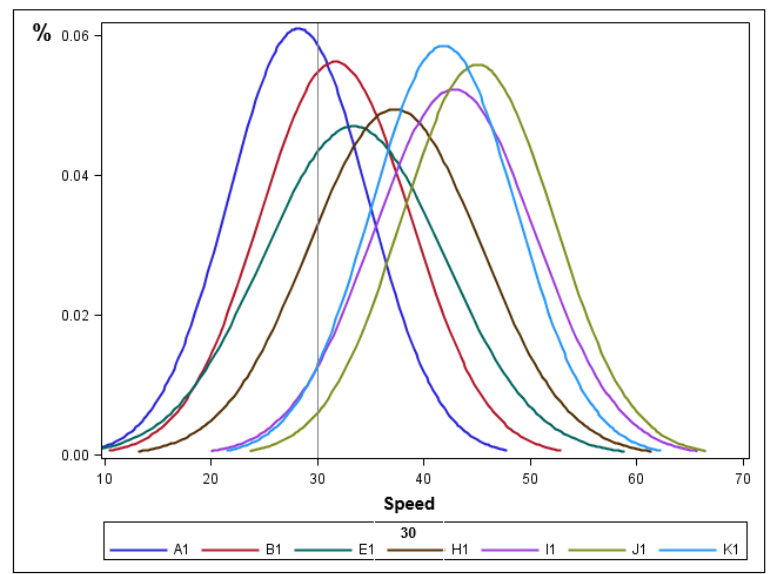

b) Sections A, B, E, H, I, J, K 


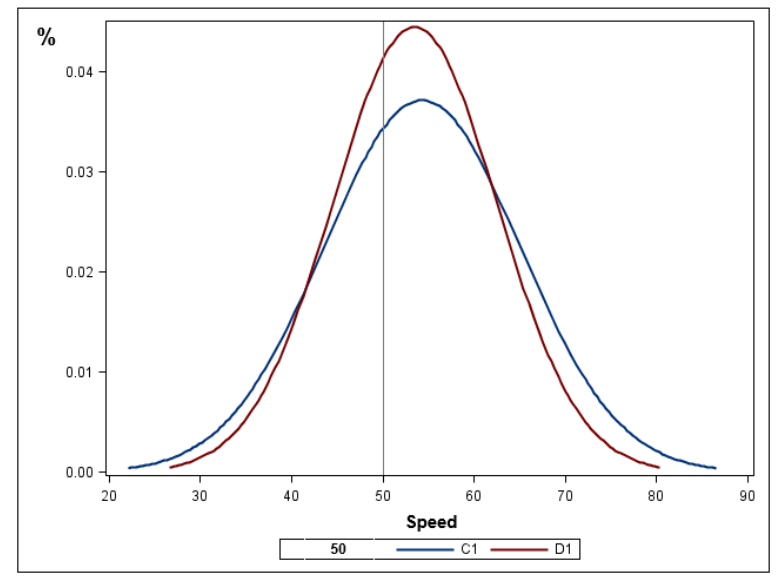

c) Sections C and D

Fig. 8. Speed distribution \%'s of all sections

\subsection{Average speed analysis for drivers who violate and comply with the speed limits}

Table 4 shows the findings from the mobile ASE measurements installed at 11 different sections according to the state of violation. Although $69.38 \%$ of the vehicles violate the speed limits in all sections, $30.62 \%$ comply with the speed limits. Sections with the lowest number of violating vehicles were $\mathrm{G}, \mathrm{A}$ and $\mathrm{K}(1.10 \%, 1.08 \%, 1.65 \%)$. Whereas sections with the highest number of violating vehicles were B, E, J and C (12.79\%, $17.13 \%, 12.06 \%, 10.70 \%)$. The sections with the highest number of complying vehicles were $\mathrm{B}$ and $\mathrm{E}(8.01 \%, 8.87 \%)$.

Table 4. Findings from the measurements according to the state of violation

\begin{tabular}{cccccc}
\hline & Speed & \multicolumn{2}{c}{ Violating } & \multicolumn{2}{c}{ Complying } \\
Section & $\begin{array}{c}\text { limit } \\
(\mathbf{k m} / \mathbf{h})\end{array}$ & $\begin{array}{c}\text { Number of } \\
\text { vehicle }\end{array}$ & $\begin{array}{c}\text { Speed } \\
\text { average } \\
(\mathbf{k m} / \mathbf{h})\end{array}$ & $\begin{array}{c}\text { Number of } \\
\text { vehicle } \%\end{array}$ & $\begin{array}{c}\text { Speed } \\
\text { average } \\
(\mathbf{k m} / \mathbf{h})\end{array}$ \\
\hline F & 20 & 3.26 & 49.00 & 0.12 & 15.14 \\
G & & 1.10 & 49.38 & 0.05 & 12.91 \\
Total & & $\mathbf{4 . 3 6}$ & & $\mathbf{0 . 1 7}$ & \\
\hline A & 30 & 1.08 & 33.91 & 1.69 & 24.48 \\
B & & 12.79 & 35.95 & 8.01 & 24.75 \\
E & & 17.13 & 38.23 & 8.87 & 23.98 \\
H & & 3.99 & 39.75 & 0.71 & 23.18 \\
I & & 2.16 & 43.73 & 0.10 & 23.08 \\
J & & 12.06 & 45.70 & 0.36 & 21.77 \\
K & & 1.65 & 42.64 & 0.08 & 24.79 \\
Total & & $\mathbf{5 0 . 8 6}$ & & $\mathbf{1 9 . 8 1}$ & \\
\hline C & 50 & 10.70 & 60.00 & 5.32 & 42.74 \\
D & & 3.47 & 58.57 & 5.32 & 42.74 \\
Total & & $\mathbf{1 4 . 1 7}$ & & $\mathbf{1 0 . 6 4}$ & \\
\hline Total & & $\mathbf{6 9 . 3 8}$ & & & \\
\hline
\end{tabular}

In the light of these findings, Independent Samples t test was carried out in order to determine whether there are differences between the averages of the average speeds for the drivers who violate and comply with the speed limits for each section. Table 5 shows the t-test results. When the $\mathrm{p}$ values are considered for the A, B, C, D, E, F, G, H, I, J, K sections, it can be observed that there is a statistically significant difference between the averages of the average speeds of 
drivers who violate and comply with the sped limits at each section since all determined values were under the 0.05 significance level.

Table 5. T-tests for average speed measurements according to violation states

\begin{tabular}{|c|c|c|c|c|c|c|c|}
\hline $\begin{array}{l}\text { Violati } \\
\text { on }\end{array}$ & Section & $\begin{array}{l}\text { Speed limit } \\
(\mathrm{km} / \mathrm{h})\end{array}$ & $\begin{array}{c}\text { Number of } \\
\text { vehicles }\end{array}$ & $\begin{array}{l}\text { Average speed } \\
\qquad(\mathbf{k m} / \mathbf{h})\end{array}$ & $\begin{array}{l}\text { Standard } \\
\text { Deviation }\end{array}$ & $\mathbf{t}$ & $\mathbf{P}$ \\
\hline $\begin{array}{l}\text { Yes } \\
\text { No }\end{array}$ & $\mathrm{A}$ & 30 & $\begin{array}{l}257 \\
402\end{array}$ & $\begin{array}{l}33.91 \\
24.48\end{array}$ & $\begin{array}{l}2.61 \\
5.56\end{array}$ & 25.45 & $<.0001$ \\
\hline $\begin{array}{l}\text { Yes } \\
\text { No } \\
\end{array}$ & B & 30 & $\begin{array}{l}3051 \\
1911 \\
\end{array}$ & $\begin{array}{l}35.95 \\
24.75\end{array}$ & $\begin{array}{l}4.15 \\
5.06 \\
\end{array}$ & 84.91 & $<.0001$ \\
\hline $\begin{array}{l}\text { Yes } \\
\text { No }\end{array}$ & $\mathrm{C}$ & 50 & $\begin{array}{l}2552 \\
1268\end{array}$ & $\begin{array}{l}60.00 \\
42.74 \\
\end{array}$ & $\begin{array}{l}6.73 \\
7.55\end{array}$ & 71.63 & $<.0001$ \\
\hline $\begin{array}{l}\text { Yes } \\
\text { No }\end{array}$ & $\mathrm{D}$ & 50 & $\begin{array}{c}827 \\
1268\end{array}$ & $\begin{array}{l}58.57 \\
42.74\end{array}$ & $\begin{array}{l}5.93 \\
7.55\end{array}$ & 41.32 & $<.0001$ \\
\hline $\begin{array}{l}\text { Yes } \\
\text { No }\end{array}$ & $\mathrm{E}$ & 30 & $\begin{array}{l}4087 \\
2116\end{array}$ & $\begin{array}{l}38.23 \\
23.98\end{array}$ & $\begin{array}{l}5.33 \\
4.66\end{array}$ & 104.09 & $<.0001$ \\
\hline $\begin{array}{l}\text { Yes } \\
\text { No }\end{array}$ & $\mathrm{F}$ & 20 & $\begin{array}{c}777 \\
29 \\
\end{array}$ & $\begin{array}{l}49.00 \\
15.14 \\
\end{array}$ & $\begin{array}{c}10.99 \\
3.51 \\
\end{array}$ & 16.55 & $<.0001$ \\
\hline $\begin{array}{l}\text { Yes } \\
\text { No } \\
\end{array}$ & $\mathrm{G}$ & 20 & $\begin{array}{c}262 \\
11 \\
\end{array}$ & $\begin{array}{l}49.38 \\
12.91 \\
\end{array}$ & $\begin{array}{l}8.92 \\
2.63 \\
\end{array}$ & 13.52 & $<.0001$ \\
\hline $\begin{array}{l}\text { Yes } \\
\text { No } \\
\end{array}$ & $\mathrm{H}$ & 30 & $\begin{array}{l}953 \\
170 \\
\end{array}$ & $\begin{array}{l}39.75 \\
23.18 \\
\end{array}$ & $\begin{array}{l}5.23 \\
6.49 \\
\end{array}$ & 36.57 & $<.0001$ \\
\hline $\begin{array}{l}\text { Yes } \\
\text { No }\end{array}$ & I & 30 & $\begin{array}{c}515 \\
24 \\
\end{array}$ & $\begin{array}{l}43.73 \\
23.08 \\
\end{array}$ & $\begin{array}{l}6.24 \\
7.81 \\
\end{array}$ & 15.65 & $<.0001$ \\
\hline $\begin{array}{l}\text { Yes } \\
\text { No }\end{array}$ & $\mathrm{J}$ & 30 & $\begin{array}{c}2878 \\
86\end{array}$ & $\begin{array}{l}45.70 \\
21.77 \\
\end{array}$ & $\begin{array}{l}5.89 \\
6.40 \\
\end{array}$ & 37.07 & $<.0001$ \\
\hline $\begin{array}{l}\text { Yes } \\
\text { No }\end{array}$ & $\mathrm{K}$ & 30 & $\begin{array}{c}393 \\
19\end{array}$ & $\begin{array}{l}42.64 \\
24.79\end{array}$ & \begin{tabular}{|l}
5.73 \\
4.71 \\
\end{tabular} & 13.36 & $<.0001$ \\
\hline
\end{tabular}

\section{Discussion and Conclusion}

The secretly measured findings of the mobile ASE set up at 11 different sections are the speeds that the "drivers are free to choose". Sections F and G with speed limit of $20 \mathrm{~km} / \mathrm{h}$ are the sections where the speed limit has been exceeded at the highest ratio (139\%). Since these sections have alignment geometrical property, have no intersections or speed bumps, there is no speed limitation due to vehicles that are turning or joining the traffic from the side or due to inspection. Whereas the speed average of section A with a speed limit of $30 \mathrm{~km} / \mathrm{h}$ is in accordance with this speed limit. There are 4 minor intersections on section A. It is thought as a result of the camera findings that vehicles have to slow down in order to give way to the vehicle making a turn in front of them at the intersection. In addition, 2 horizontal curves and 2 speed bumps on this section also decrease the driving speeds. Hence, compliance with the speed limit is high in section A and low in sections F and G [18,37,38]. Even though section A is located close to the faculty settlement areas, there are pedestrian crossings along the section within the scope of the "pedestrian priority road" application. It is thought that speeds close to the average speed limits are used on these sections due to their geometric, physical and application characteristics. In addition, it is also thought that the speed limits at sections $\mathrm{F}$ and $\mathrm{G}$ are not considered to be reasonable by the drivers at first glance and that there is a need for an optimal speed limit regulation $[8,11,13,39]$. Average speed for each section with the same speed limit $(30 \mathrm{~km} / \mathrm{h})$ can be listed in increasing order as A, B, E, H, K, I and J. In addition, it is also thought that speeding behavior is accepted more by the drivers on sections I and $\mathrm{J}$ since pedestrian traffic is at a minimum level along these sections. It is also thought that the speed limit feeling instilled in the driver due to the physical state of each section is also effective. 
It has been realized that traffic safety is not sufficient in the campus road network. A higher compliance to the speed limits may be attained by a better communication and information strategy as well as an enforcement for the follow-up of violations. Sharing of information on both speed data and violation enforcement is required in addition to determining a consistent strategy that will direct the driver attitudes towards a higher compliance to speed limits [40]. In addition, it is thought that the speed limits on some sections are not considered to be reasonable from the driver's perspective and that there is a need for an optimal speed limit regulation. Even though the approach for adjusting the speed limits should also increase the respect of the drivers to the speed limits, it should not be neglected that the setting was a university campus. The point that should be taken into consideration for speed limit regulation is that the sections are inside a university campus and hence a regulation should be made that will not endenger pedestrian safety.

\section{Acknowledgments}

This work is a part of the Project 2011010102007 'Application of the Mobile Automatic Plate Recognition System to the Akdeniz University Campus Against High Speed Problem and Evaluation of Effectiveness', which is financed by the Akdeniz University Scientific Research Projects Management Unit.

\section{References}

[1] KGM, Karayollarinda Hiz, KGM, 2014.

[2] Goldenbeld, C., van Schagen, I., The effects of speed enforcement with mobile radar on speed and accidents: An evaluation study on rural roads in the Dutch province Friesland. Accident Analysis \& Prevention, 37(6), 1135-1144, 2005.

[3] Sahin, Ö., Hiz denetiminde otomatik video-radar sistemlerinin uygulanabilirliği, Doctoral dissertation, SDU Fen Bilimleri Enstitüsü, 2004.

[4] Aydın, C., Trafik Güvenliği ve Eğitimi. Trafik, 2009.

[5] Bolcu, A., Trafik Güvenliği, Çă̆ın Polisi Dergisi, 2, 2009.

[6] Acar, N., Aşırı Hızın Trafik Kazalarına Etkisi. Çă̆ın Polisi Dergisi, 2009.

[7] Cascetta, E., Punzo, V. and Montanino, M., Empirical Evidence of Speed Management Effects on Traffic Flow at Freeway Bottleneck, TRB 2011 Annual Meeting, 2011.

[8]Collins, G., Traffic Flow İmprovements with Average Speed Enforcement, In International Conference on Intelligent Transport Systems, Birmingham, United Kingdom, 2007.

[9] De Pauw, E., Daniels, S., Brijs, T, Hermans, E., Wets, G., Automated Section Speed Control on Motorways: An Evaluation of the Effect on Driving Speed. Accident Analysis \& Prevention, 73, 313-322, 2014.

[10] Koy, T. and Benz, S., Automatic Time-Over-Distance Speed Checks İmpacts on Driving Behaviour and Traffic Safety, The 6th ITS World Congress and Exhibition on Intelligent Transport Systems and Services, Stockholm, 2009.

[11] Soole, D., Fleiter, J., Watson, B., Point-to-Point Speed Enforcement. Report No: AP-R41512., 2012.

[12] Speed Check Services, SPECS Safety Cameras-M4 10-12 Technology Upgrade. Speed Check Services, 2009.

[13] Stefan, C., Automatic Speed Enforcement on the A13 Motorway (NL): Rosebud WP4 Case B Report. Austrian Road Safety Board (KfV), 2005.

[14] Australian Transport Council, National Road Safety Strategy 2011-2020, Australian Transport Council, 2011. 
[15] Cameron, M.H., Diamantopoulou, K., Clark, B., Langford, J., Identifying Traffic Enforcement Practices and Opportunities in Western Australia. Curtin Monash Accident Research Centre, 2011.

[16] Gil, MJM., Malenstein, UPMJ, Innovative Technology for Monitoring Traffic, Vehicles and Drivers, Police Enforcement Policy and Programmes on European Roads, 2007.

[17] Høye, A., Speed Cameras, Section Control, And Kangaroo Jumps - A Meta-Analysis. Accident Analysis \& Prevention, 73, 200-208, 2014.

[18] Lynch, M., White, M., and Napier, R., Investigation into the Use of Point-to-Point Speed Cameras, NZ Transport Agency Research Report 465, 2011.

[19] Montella, A., Punzo, V., Chiaradonna, S., Mauriello, F., Montanino, M., Point-to-Point Speed Enforcement System: Speed Limits Design Criteria and Analysis of Drivers' Compliance. Transport. Res. Part C, 53, 1-18, 2015.

[20] Simcic, G, Section Control: Towards a More Efficient and Better Accepted Enforcement of Speed Limits? Speed Fact Sheet, 2, 2009.

[21] Soole, DW., Fleiter, Judy J., Watson and Barry C., Point-to-Point Speed Enforcement: Recommendations for Better Practice. Australasian Road Safety Research Policing and Education Conference, Brisbane, 2013.

[22] Speed Check Services, Temporary Roadworks Speed Enforcement - M1. Speed Check Services, 2006.

[23] Speed Check Services, SPECS: Results. Speed Check Services, 2009.

[24] Pau, M., Angius, S., Do speed bumps really decrease traffic speed? An Italian experience. Accident Analysis \& Prevention, 33(5), 585-597, 2001.

[25] Akpa, N.A.E.E., Booysen M.J. and Sinclair M., The İmpact of Average Speed Over Distance (ASOD) Systems On Speeding Patterns Along The R61, In Proceedings of The First International Conference on the Use of Mobile Informations and Communication Technology, Africa, 2014.

[26] Elvik, R., Christensen, P., Amundsen, A., Speed and Road Accidents: an Evaluation of the Power Model. Nordic Road and Transport Research, 17(1), 2005.

[27] Roads and Traffic Authority, Speed Problem Definition and Countermeasure Summary, New South Wales: Roads and Traffic Authority, 2000.

[28] Fleiter, J., Lennon, A., Watson, B., How Do Other People İnfluence Your Driving Speed? Exploring the 'Who' and the 'How' of Social İnfluences on Speeding from a Qualitative Perspective. Transportation Research Part F: Traffic Psychology and Behaviour, 13(1), 4962, 2010.

[29] Soole, DW., Watson, BC., Fleiter JJ., Effects of Average Speed Enforcement on Speed Compliance and Crashes: A review of the Literature. Accident Analysis \& Prevention, 54, 4656, 2013.

[30] Freeman, J.E., Watson, B., An Application of Stafford and Warr's Reconceptualization of Deterrence to a Group of Recidivist Drink Drivers. Accident Analysis \& Prevention, 38(3), 462471, 2006.

[31] Taylor, M. C., Lynam, D. A., Baruya, A., The Effects of Drivers' Speed on the Frequency of Road Accidents. TRL Report No:421, 2000.

[32] Cameron, M., Development of Strategies for Best Practice in Speed Enforcement in Western Australia, Supplementary Report, Monash University Accident Research Centre, 2008.

[33] Roberts, CA., Brown-Esplain, J., Technical Evaluation of Photo Speed Enforcement for Freeways, Arizona Report 596, 2005.

[34] Speed Check Services, Temporary Roadworks Speed Enforcement - M6. Speed Check Services, 2007. 
[35] Young, K.L., Regan, M. A., Intelligent Transport Systems to Support Police Enforcement of Road Safety Laws. ATSB Research and Analysis Report No: 2007-02, 2007.

[36] Montella, A., Persaud, B., D'Apuzzo, M., Imbriani, L.L., Safety evaluation of an automated section speed enforcement system. Transportation Research Record: Journal of the Transportation Research Board, 2281, 16-25, 2012.

[37] Lynch, M., Forward Design Study: Introduction of Point to Point Speed Cameras in the $A C T$, AECOM Australia, 2010.

[38] Yayla, N., Karayolu mühendisliği, Birsen Yayınevi, 2011.

[39] Stoelhorst, H., Reduced Speed Limits for Local Air Quality and Traffic Efficiency. The 7th European Congress and Exhibition on Intelligent Transport Systems and Services, Geneva, Switzerland, 2008.

[40] Montella, A., Punzo, V. and Montanino, M., Analysis of Drivers' Compliance to Speed Limits Enforced with an Automated Section Speed Enforcement System. Transportation Research Board 91st Annual Meeting, 2012. 